\title{
Controversies Surrounding the Use of Long-Acting Injectable Antipsychotic Medications for the Treatment of Patients with Schizophrenia
}

\author{
John M. Kane $e^{1,2,3} \cdot$ Joseph P. McEvoy ${ }^{4}$ Christoph U. Correll ${ }^{1,2,3,5} \cdot$ Pierre-Michel Llorca $^{6,7,8}$
}

Accepted: 23 August 2021 / Published online: 11 October 2021

(c) The Author(s) 2021

\begin{abstract}
Schizophrenia is a serious mental illness that requires continuous and effective long-term management to reduce symptoms, improve quality of life, and prevent relapse. Oral antipsychotic medications have proven efficacy for many patients taking these medications; however, a considerable number of patients continue to experience ongoing symptoms and relapse, often due to lack of adherence. The advent of long-acting injectable (LAI) formulations of antipsychotic medications provided an opportunity to improve treatment adherence and overall patient outcomes. Despite data to support LAI efficacy, safety, and improved adherence over oral formulations, there are several misconceptions about and barriers to LAI implementation within a standard of care for patients with schizophrenia. Areas of resistance around LAIs include (1) doubts regarding their benefits outside of improved adherence, (2) questions regarding their prescribing to a broader population of patients with schizophrenia, (3) when to initiate LAIs, (4) concerns regarding the safety of LAIs in comparison with oral medication, and (5) the most effective ways to educate healthcare providers, patients, and caretakers to enable appropriate LAI consideration and acceptance. Here, we discuss these key controversies associated with LAIs and provide supportive evidence to facilitate LAI use in a manner that is constructive to the clinician-patient relationship and successful treatment.
\end{abstract}

\section{Plain Language Summary}

Schizophrenia is a mental condition that affects how a person acts, thinks, sees, and interprets their surroundings and expresses how they feel. Relapse can lead to hospitalization and other poor outcomes. Almost half of patients with schizophrenia tend to start and stop treatment, which can cause more relapses and make symptoms worse over time. Using antipsychotic drugs long term can reduce impairing illness symptoms and improve patient quality of life. Consistent use of antipsychotic drugs can help prevent relapse. Available antipsychotic drugs can be taken by mouth (oral) or by an injection. Oral drugs have to be taken every day, whereas long-acting injections (LAIs) of antipsychotic drugs can be given less often, such as every 2 weeks, monthly, and up to once every 3 months. In the past, LAIs were used only when oral antipsychotic drugs did not work, which was usually because patients did not take them every day. However, LAIs also work as an early treatment, which can be better for the patient. Patients taking LAIs skip fewer doses and so may have fewer relapses and hospitalizations. Because LAIs have to be given at the clinic, patients get more regular medical care and tend to keep taking their medicine for longer. Most LAI side effects are similar to those of oral antipsychotic drugs. Despite this, some clinicians hesitate to prescribe LAIs. More education for clinicians and patients about LAIs could increase interest and use. Recovery and relapse prevention are the main treatment goals for patients and their care team, and LAIs can improve both.

John M. Kane

JKane2@northwell.edu

1 Behavioral Health Services, Zucker Hillside Hospital, Northwell Health, 75-59 263rd St, Glen Oaks, NY 11004, USA

2 Donald and Barbara Zucker School of Medicine at Hofstra/Northwell, Hempstead, NY, USA

3 Feinstein Institutes for Medical Research, Institute of Behavioral Science, Manhasset, NY, USA
4 Medical College of Georgia, Augusta University, Augusta, GA, USA

5 Charité-Universitätsmedizin Berlin, Berlin, Germany

6 Fondation FondaMental, Créteil, France

7 Clermont-Ferrand University Hospital Center, Clermont-Ferrand, France

8 University of Clermont Auvergne, Clermont-Ferrand, France 


\section{Key Points}

The use of long-acting injectable (LAI) antipsychotic medications is a well-tolerated and effective means to help address low levels of treatment adherence in patients with schizophrenia.

Despite the benefits of LAIs, several barriers prevent their widespread adoption, such as controversies/issues related to benefits outside of improved adherence, defining the target patient population, when to initiate LAI treatment, relevance of adverse effects with LAIs, healthcare provider education and training, and presenting treatment recommendations to patients.

These controversies/issues perpetuate a negative perception of LAIs that is unsupported by current data and that can be countered with education and training efforts.

\section{Introduction}

Schizophrenia is a significant medical condition with a global prevalence of $\sim 20$ million in 2017 and an incidence (during 2017) of over 1 million [1]. Incidence rates vary among subgroups and are typically higher in males than in females, in migrants than in native born, and in urban than in mixed urban/rural settings [2]. Effective management of schizophrenia requires early intervention and continuous long-term treatment to reduce symptoms, maintain function, improve quality of life [3], and prevent relapse [4, 5]. A long duration of untreated psychosis is often associated with poorer outcomes [6, 7], and patients who discontinue their treatment can interrupt improvement, exacerbate the illness [8], and have a fivefold greater chance of relapse [5].

Despite the availability of effective oral antipsychotic (OA) treatments, long-term adherence is low [3, 9], which can frequently result in relapse, rehospitalization, and poor outcomes [3, 10,11]. Poor adherence is considered an important characteristic in determining whether a longacting injectable (LAI) antipsychotic medication will help a patient achieve their therapeutic goal, with LAI use and other strategies often being implemented as a means to help overcome low levels of adherence [8, 12, 13]. Firstgeneration antipsychotic (FGA) LAIs [14, 15] (Table 1) were introduced over 50 years ago with the goals of improving adherence and reducing symptom exacerbation, relapse, and rehospitalization [16, 17]. The concept of LAIs for schizophrenia was not initially well received by the medical community or patients because of concerns over increased side effects, lack of efficacy, and that psychiatrists were restricting patient freedom by imposing a treatment without due regard to patients' feelings or rights [10, 18]. Although first-generation OAs and LAIs remain available, a series of second-generation antipsychotic (SGA) LAIs and OAs [14, $15,19]$ have emerged (Table 1) with improved tolerability $[16,20]$. Despite recent evidence of the benefits of early LAI use [21, 22], many barriers to their adoption exist, including the overestimation of patient adherence, patient refusal, and perceived coercion [23].

Guidelines and recommendations have been released by the American Psychiatric Association (APA), individual states, and other countries and organizations to improve both quality of care and treatment outcomes in patients with schizophrenia [24-28]. Although these documents tend to have general consistencies, recommendations beyond firstline treatment are unclear, and the amount of published literature in this area is limited. Also, the advantages and disadvantages of LAIs in clinical practice remain controversial, limiting the number of LAI prescriptions actually given to those patients who fall within the often relatively narrow suggested LAI indications, such as already fully established nonadherence, several prior relapses, and patient preference [18, 24-27]. Here, we discuss the controversies surrounding LAI use and provide evidence (where available) and direction (based on expert opinion and clinical experience where published literature is not available) to support LAI implementation. The controversies presented are as follows: presence of benefits outside of improved adherence, defining the target patient population, when to initiate treatment, healthcare provider education and training, and how to present treatment recommendations to patients. Negative and positive perceptions of LAIs across these five controversies are discussed in the following sections and summarized in Table 2 .

\section{What Benefits Do Long-Acting Injectables (LAls) Provide?}

\subsection{Improved Adherence}

Approximately 40-50\% of patients with schizophrenia may be nonadherent with their antipsychotic medication, by either not filling or not using an antipsychotic prescription [29-31]. One of the most commonly discussed benefits of LAIs is increased adherence over OAs [16, 27, 32]; therefore, many believe that improving adherence should be the only focus when developing a standard of care that involves LAIs. Although patients can demonstrate nonadherence with LAIs and the benefits of LAIs can be mitigated or even negated by non- or partial adherence [33-35], skipped 


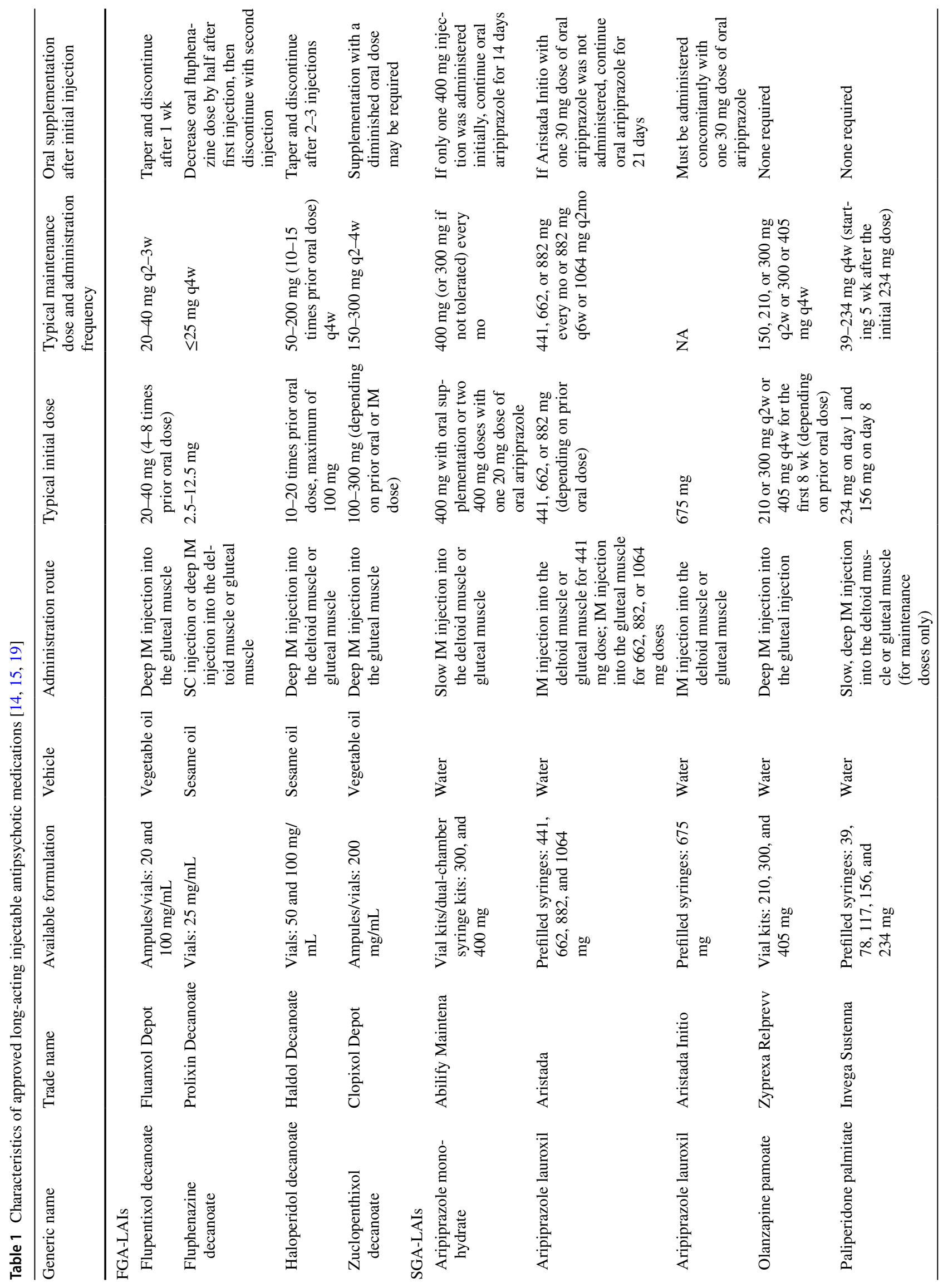


doses are known sooner because of the need for a professionally administered injection versus self-administration of pills, and relapses are delayed because of the longer half-lives of LAIs [36]. However, because many patients may be nonadherent [29-31], increased use of LAIs can support relapse prevention, even early in treatment [22]. Specifically, sustained adherence was reported after a first episode of schizophrenia with administration of the LAI versus the oral formulation of risperidone, where $95 \%$ of patients in the LAI group versus $33 \%$ in the OA group were rated as having "excellent" adherence during the 1-year study, with an $85 \%$ relative risk reduction for relapse in the LAI group [22]. Overall, adherence to LAIs can be tied to beneficial outcomes [22], highlighting the important relationship across medication adherence, safety, relapse prevention, and feasibility of use. Most important, LAIs provide several therapeutic benefits over OAs that go beyond improved adherence. In a meta-analysis of studies comparing LAIs with OAs across three designs (randomized trials, mirror image studies, and cohort studies), LAIs were consistently associated with significantly lower risk of hospitalization and/or relapses [37]. Moreover, LAIs were superior to OAs in $20 \%$ of the 337 reported outcomes, whereas OAs were not superior to LAIs on any outcome, including tolerability. It should be noted that, in a clinical trial setting, adherence to OAs is likely higher than in clinical practice, whereas adherence to LAIs is thought to be similar because of the need for clinic visits for injections and immediate awareness when an injection is missed. Together, this may mean that the incremental benefits of LAIs over OAs observed in clinical trials would be even greater in a "real-world" setting, as suggested by systematic review where more pragmatic trials were more likely to demonstrate LAI benefit [38].

\subsection{Greater Tolerability}

The APA recommends close monitoring of both efficacy and side effects upon initiating treatment of schizophrenia $[26,28]$. While increased treatment adherence is a welldiscussed benefit of LAIs, there is concern regarding the safety and feasibility of using these medications and how they may impact recovery. A negative perception of LAI versus OA safety has emerged, partially from experiences with short-acting intramuscular injections often used in emergency or inpatient settings and FGA-LAIs, which have been associated with injection-related adverse events and a sometimes-reported higher occurrence of extrapyramidal symptoms and tardive dyskinesia $[16,39]$. On the other hand, perceptions about the relative safety of OAs may be influenced by poor adherence [40, 41]. Importantly, SGALAIs have a different aqueous formulation/suspension than FGA-LAIs, and this has helped reduce the occurrence of 


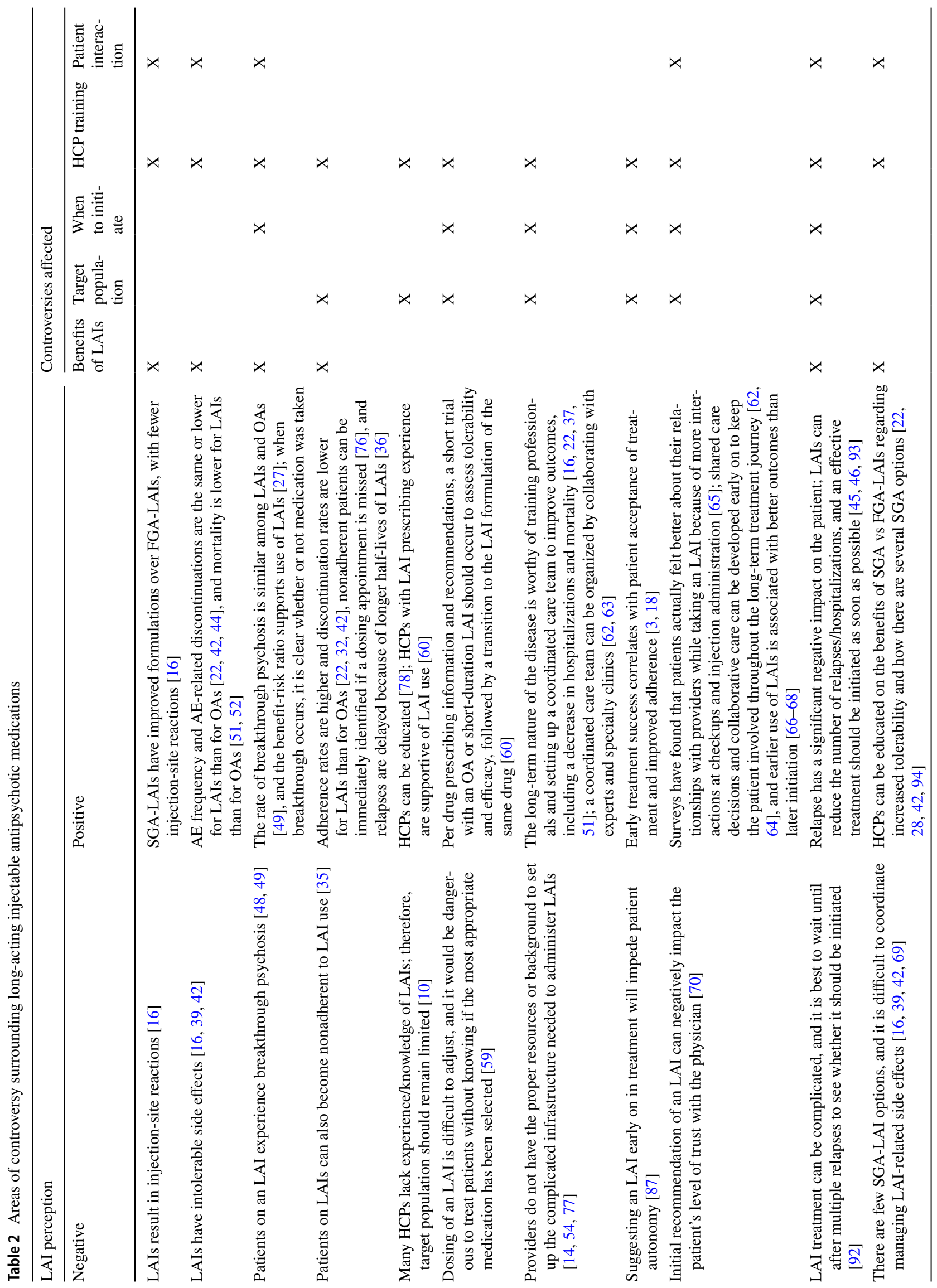




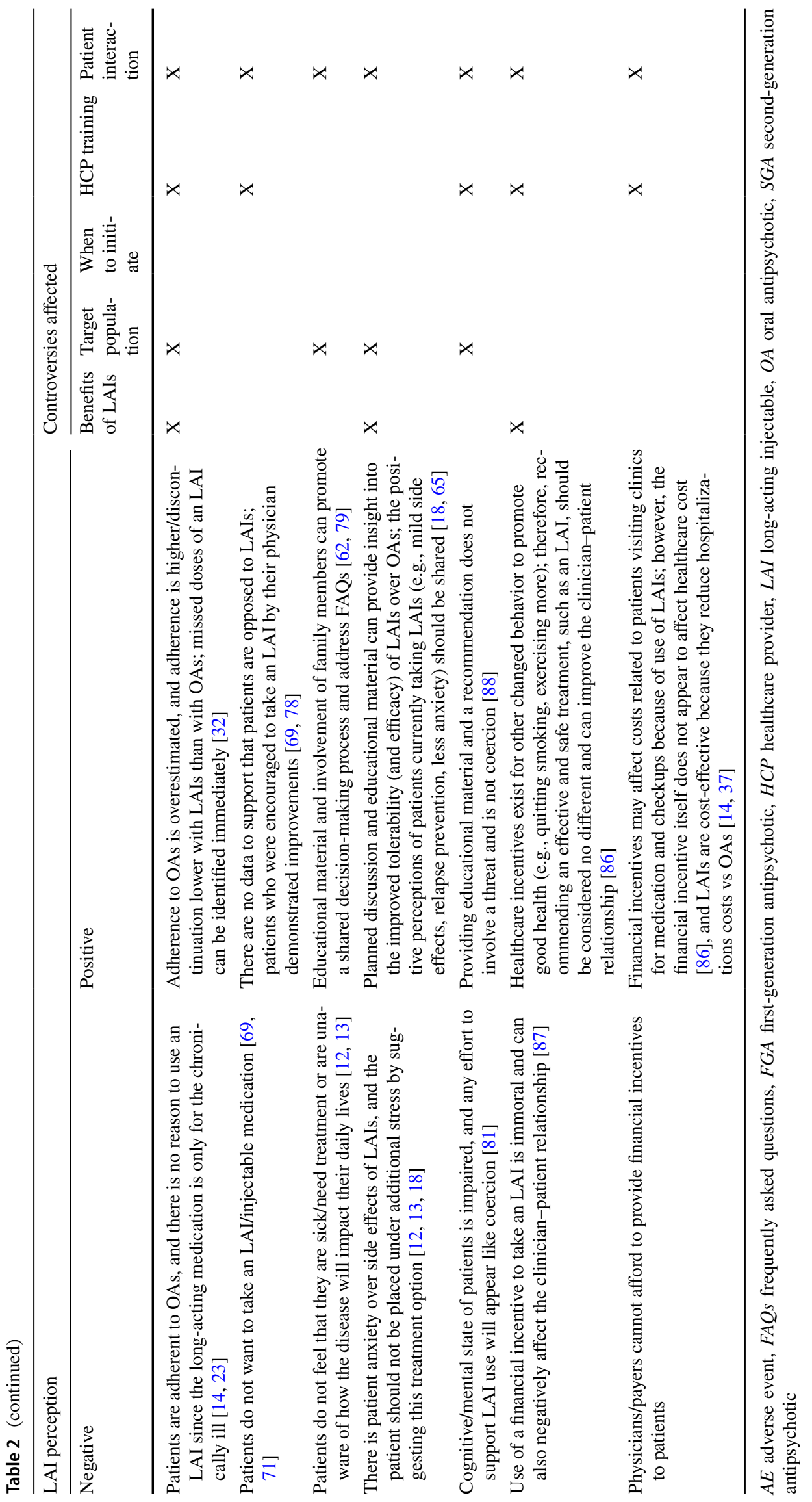


injection-site-related events [16]. Although findings from a recent meta-analysis indicated that akinesia, low-density lipoprotein cholesterol changes, and increased anxiety were observed at higher rates with SGA-LAIs than with the same antipsychotic medication given orally, the overwhelming majority of adverse effects (approximately 97\%) occurred with similar frequencies between formulations of antipsychotic medications, and increases in serum prolactin levels were less pronounced with SGA-LAIs [42]. The American Society of Health-System Pharmacists recently provided a consensus statement noting how the likelihood of certain side effects differs across agents (i.e., risk of post-injection syndrome with olanzapine pamoate) and that treatment can be successful with proactive monitoring and management of symptoms [43]. Finally, while neuroleptic malignant syndrome (NMS) - a potentially life-threatening adverse effect of antipsychotic medications for which abrupt cessation of the offending agent is recommended-has been raised as a concern for LAI use, a recent patient-level meta-analysis of 662 published case reports of NMS did not show worse outcomes with LAIs than with OAs [44]. Despite the presence of some side effects, an assessment of benefit/risk ratios reported greater benefit with SGA-LAIs than with either FGA-LAIs or OAs [27].

\subsection{Relapse Prevention and Fewer Hospitalizations}

Recovery/relapse prevention is the ultimate goal of treatment for both patients with schizophrenia and their treating clinicians. Relapse has a negative impact on the patient, with the number of relapses significantly correlating with greater deterioration of the patient over time [45]. Patients with firstepisode psychosis do not respond as well to antipsychotic medications after a relapse as they did during their initial treatment $[45,46]$. A criticism of LAIs is that psychosis breakthrough can still occur during treatment [47], which may raise the question of why LAIs would be preferred over OAs. However, the categorization of psychosis breakthrough on antipsychotic maintenance medication (BAMM) in patients taking an LAI is approximately $21-31 \%$ [48, 49], and psychosis relapse rates are comparable during ongoing treatment with LAIs and OAs [49]. In other words, oral and LAI formulations do not differ in efficacy if patients are consistently taking the former. Because LAIs must be administered by a clinician, a crucial advantage is confirmation of treatment adherence, even at relapse, which is not the case with OAs. Additionally, patients who had only been treated with OAs were surveyed and reported to be more accepting of potential LAI treatment because of a greater expectation of relapse prevention [18].

Higher adherence to LAIs than to OAs can play a role in relapse prevention because adherence was significantly associated with both fewer relapses and psychotic symptom exacerbations in the LAI versus oral risperidone study mentioned earlier [22]. Awareness of factors that are potentially predictive of breakthrough psychosis or relapse can help inform patient monitoring and care management tactics. Risk factors reported to be associated with BAMM include illness instability at treatment onset, substance use, and tardive dyskinesia $[49,50]$.

\subsection{Reduced Treatment Discontinuation}

A marker of tolerability, efficacy, and feasibility of use of a medication can be the proportion of patients who do not discontinue treatment. A meta-analysis of randomized controlled trials of patients taking an LAI or OA identified that discontinuation rates because of adverse events, serious event occurrence, or death were similar among the groups [42]. Another study comparing LAI and oral risperidone found that the frequency of discontinuations because of adverse effects was twice as high for the oral versus LAI formulation ( 21 vs. $10 \%$ ) and that there were fewer discontinuations because of lack of efficacy in the LAI group [22]. A more stable treatment duration because of fewer discontinuations and relapses can lead to improved outcomes for patients. In general, antipsychotic medications reduce the mortality rates of patients with schizophrenia from those observed in untreated patients [51,52]. An analysis of mortality rates across first- or second-generation OAs or LAIs reported the lowest mortality rates with SGA-LAIs and a $33 \%$ overall lower risk of death during LAI versus equivalent oral use [51]. Additionally, compared with antipsychotic medication users, nonusers and early discontinuers had a 214 and $174 \%$ higher risk of death, respectively, with the relative gap increasing over time [53]. The comparable or lower discontinuation rates because of intolerance with LAIs versus OAs, in addition to the significantly lower mortality rates, support the overall benefit of LAIs.

\section{Who Should be Prescribed an LAI?}

\subsection{Not Limited to Patients Who are Nonadherent}

Prescribing patterns for LAIs vary across the globe but can be as low as $10 \%$ in the USA [10]. Minimal use of LAIs can be somewhat attributed to a lack of knowledge and familiarity for both healthcare providers and patients as well as their families/caregivers [10]. The limited number of prescribers who have experience with LAIs may lead to their use in only a small number of patients with a medical history of/or risk factors for nonadherence with OAs versus broadening LAI consideration to a wider range of patients. The specific techniques for LAI administration (i.e., proper needle length) are often based on patient factors, such as 
patient weight, injection-site preference, or injection-site reactions [54]. Both care and experience are needed during LAI administration because local reactions can occur if the LAI is not injected correctly or injected too frequently in the same location [54]. Furthermore, access to expert consults for unexpected symptoms or adverse events that may occur after injection are important [54], and it may be more feasible in some settings to focus LAI use on one subset of patients. In addition to these safety concerns, implementing broad use of LAIs, versus limiting access to obviously nonadherent patients, may result in greater variation in the healthcare providers administering the injections over time [54], resulting in a lack of continuity for the patient.

A complication of targeting nonadherent patients is that the definition of "nonadherence" can vary among practices, regions, and countries; therefore, broadening the target population for LAI use may bypass any issues related to differences in terminology. Awareness of the specific drivers of nonadherence to schizophrenia treatments-including whether it is intentional (e.g., side effect avoidance, lack of illness insight) or unintentional (e.g., substance abuse, cognitive/mental impairments, lack of support)—is needed to appropriately address the issue of nonadherence [55]. LAIs have great potential to benefit a variety of patients instead of just those who have frequent relapses, may pose a threat to others, have low illness insight, have prior positive experience with LAIs, or simply prefer LAIs over OAs [27], and healthcare providers are voicing their interest in broader use of LAIs. A 2013 survey of French psychiatrists reported that, in addition to nonadherence, the factors with the highest rating for consideration of an LAI prescription were prior LAI experience, prior relapse, and risk to others [56]. Also, a 2016 survey of researchers and clinicians with LAI experience reported a strong consensus for prescribing LAIs not only to those who are nonadherent but also to patients with a broader range of conditions, such as certain histories (i.e., multiple hospitalizations/relapses, violence, suicide attempt, substance abuse), poor illness insight, cognitive impairment, and in patients aged 18-25 years [57]. Early introduction of LAIs can provide increased competitive employment/independent living and decreased disability/hospital admissions compared with OA treatment [58], supporting LAI use in a broader range of patients.

Although LAIs improve adherence rates, their less frequent administration schedule ( $2-12$ weeks between injections, depending on the LAI) also results in reduced flexibility to make dose adjustments and a longer time for the drug to reach steady state [59]. These disadvantages related to the administration schedule for LAIs versus OAs may lead some clinicians to limit LAI use to only select patients (e.g., highly nonadherent, multiple relapses); however, these barriers are worth overcoming to increase the number of patients who might benefit from LAI treatment. Schizophrenia treatment is a long-term challenge and warrants the development of care systems and strategies that can benefit many patients over time.

\section{When Should Treatment with an LAI Begin?}

\subsection{First-episode Psychosis or Early-stage Schizophrenia}

It is not clear what medication will be most effective when patients are first diagnosed with schizophrenia. With this in mind, many clinicians believe that LAIs should not be used until patients experience multiple relapses, are chronically ill, and/or overtly demonstrate nonadherence. While treatment with an OA prior to LAI use is the preferred clinical practice to establish initial efficacy and tolerability, the optimal duration of this initial treatment is unclear [60].

Patients should be provided the best opportunity for success when initiating a treatment for schizophrenia, and positive experiences with a medication can facilitate patient acceptance of a treatment regimen [18]. The benefits of LAIs versus OAs discussed earlier support implementation of LAIs as soon as possible after the first episode of psychosis. Additionally, early LAI implementation and longer LAI treatment duration are predictors of improved Global Assessment of Functioning scores [3].

Experts agree that schizophrenia cannot be considered truly refractory to treatment until there is at least one attempt of LAI use [60, 61]; therefore, the argument can be made to implement LAIs after one or two treatment failures in terms of lack of efficacy. One study investigating oral versus LAI risperidone in patients with first-episode psychosis reported much stronger adherence with the LAI [22]. Additionally, overall medication adherence within the first 6 months of study treatment correlated with adherence in the subsequent 6-month period, supporting early introduction of treatments known to improve adherence.

Clinicians should instead destigmatize nonadherence and explain that most patients will have trouble taking medication; nonadherence does not mean that the patient is a "bad" person or patient. Adherence monitoring can be a collaborative approach involving the patient, family, and healthcare providers. Clinicians can help patients develop self-monitoring systems to preserve autonomy and control while also involving family members to help monitor patient adherence $[62,63]$. In one study, patients were 1.6 times more likely to adhere to a medication if a care supervisor were involved (usually a close relative) versus usual treatment; the group with improved adherence also demonstrated significantly more improvement in symptoms and functioning [64]. In addition, many patients actually felt better about their 
relationships with their healthcare team because of more frequent or regularly scheduled contact during receipt of LAIs [65]. In addition, less time needs to be spent discussing whether or not the patient has been taking the medication. Nevertheless, the injection interval should not determine the frequency of visits to mental healthcare providers.

As noted, there are a wide range of benefits to LAI use, and the advantages of early implementation of an LAI should outweigh potential concerns over its use for schizophrenia. Treatment with an LAI should not be delayed because later versus earlier initiation of LAIs has been associated with poorer symptomatic and functional outcomes [66-68].

\section{Why Do Healthcare Professionals Not Prescribe LAls and How Can Potential Concerns be Addressed?}

\subsection{Negative Perceptions}

Another factor preventing clinicians from prescribing LAIs may be initial negative experiences with less tolerable FGALAIs and being unaware of all of the SGA-LAI options $[10,16,69]$. Some healthcare providers may also feel that suggesting an LAI to a patient may appear insulting, show evidence of a lack of trust, and negatively affect the clinician-patient relationship [70].

Clinicians may not be portraying LAIs to patients in an appropriate manner, either assuming patients will not overcome discomfort with needles or presenting the option with ambivalence instead of emphasizing key benefits [71]. Often, clinicians assume patient objection to LAIs [70]; however, this objection is unsupported by available data [69]. In a cluster-randomized trial of patients with firstepisode psychosis and early-phase disease with less than 5 years of antipsychotic medication use, time to hospitalization was significantly delayed in the group of patients whose clinicians were trained to encourage treatment with an LAI early in the illness compared with a control group receiving care as usual that did not emphasize LAI use (44\% reduction in first hospitalization in the LAI group) [21]. These data highlight the important role that treatment teams have in supporting patients to select a beneficial therapy regimen and that presenting LAIs as a positive treatment option based on data can result in therapeutic benefits. In that trial, $86 \%$ of young early-phase patients showed willingness to try an LAI, with $91 \%$ receiving an LAI, when it was presented in an informed shared decision-making model [21].

\subsection{Lack of Guidelines}

Clear guidelines for recommending LAI use are needed to help align and guide clinicians. The APA guidelines for the treatment of schizophrenia were recently updated; however, there are no recommendations regarding early implementation of LAIs [26], and this lack of guidance can strongly contribute to less frequent LAI prescribing by healthcare providers [23]. Other more regional guidelines are beginning to incorporate early LAI use into their recommendations. For example, the recently updated Florida Medicaid guidelines recommend use of an LAI even in patients with first-episode psychosis who respond to and tolerate OAs and are currently adherent [24]. Also, the National Council for Behavioral Health considers LAIs to be a better option than OAs for the early treatment of schizophrenia and that their implementation should not be restricted to only patients who have experienced several relapses [25]. Outside the USA, the 2009 clinical practice guidelines promulgated by the Agency for Health Technology Assessment and Research in Spain do not recommend LAIs for patients with first-episode psychosis or early-stage schizophrenia; however, these guidelines are $>5$ years old and are subject to update [72]. Both the Royal Australian and New Zealand College of Psychiatrists and the Asia-Pacific recommendations suggest that LAIs be considered in first-episode psychosis and early-stage disease $[73,74]$.

\subsection{Clinician Education}

Unfortunately, a major barrier to LAI use can be that providers are not adequately equipped to support patients in the medication decision-making process [75]. To help encourage the appropriate use of LAIs, clinicians should undergo training early on and be educated to correct misconceptions and base their perception of LAIs on the available evidence reviewed earlier. For example, one study reported that, out of 206 patients, only $28 \%$ were aware of having a schizophrenia diagnosis, and $32 \%$ claimed that they did not receive any information about their condition or its treatment [65]. To facilitate the provision of support to patients, healthcare professionals can employ effective psychosocial strategies across three categories: educational (i.e., information about the disease and medications), behavioral (i.e., understanding of patient attitude toward the illness and treatment), and affective (i.e., familial and other support) [62]. In fact, LAI implementation may allow for this additional support as less time will be spent during clinic visits discussing adherence issues.

Clinicians may be hesitant to use LAIs for reasons including limited knowledge about drug pharmacokinetics and appropriate dose selection [15], an overestimation of patient adherence to OAs $[14,56]$, and a lack of awareness of the benefits of SGA versus FGA-LAIs or versus OAs [42, 76]. In addition, clinicians often appreciate the freedom to modify doses for patients, and limiting this ability with the use of LAIs could generate concerns. 
LAIs have different dosing parameters than OAs because of their long half-lives and delayed release, both of which can appear to make dose optimization more complicated and be a barrier for clinicians who are dependent on being able to adjust doses rapidly. For example, clinicians may wish for the ability to initiate an LAI at a higher dose for patients with a history of higher OA dose requirements or prescribe a lower initial dose in elderly patients or those who have experienced dose-dependent antipsychotic medicationrelated side effects [60]. However, these challenges can easily be met, given the range of different medications, doses, and injection intervals that are currently available as LAI formulations. In fact, in some cases, patients are on higher than necessary doses because their adherence is not optimal.

In addition, some LAIs require OA coadministration in the beginning of LAI use until therapeutic blood levels are reached [15], which in turn temporarily increases treatment complexity. However, these requirements for coadministration are brief, and the establishment of an LAI strategy is a long-term investment. Additionally, there are very good data establishing effective doses for LAIs [14, 15], and conversions from oral to LAI formulations are not prohibitively complex. Clinicians may also find it reassuring to know that their patients are consistently receiving the exact dose that was prescribed. Regarding differences between FGA and SGA-LAIs, a survey conducted in France reported that $86 \%$ of clinicians would strongly encourage use of SGA-LAIs for schizophrenia versus only $48 \%$ supporting the use of FGALAIs [27]. Educating providers on the safety profiles of FGA versus SGA-LAIs and highlighting the differences discussed earlier could greatly impact clinician interest and confidence in prescribing an LAI.

\subsection{Limited Resources}

Clinicians who are critical toward considering LAIs may not change their minds with additional education, and an alternative option is to develop care systems with providers who appreciate the benefits of LAIs. Having the clinical team educated on currently available LAIs (Table 1) and data supporting their efficacy, effectiveness, and acceptability can facilitate appropriate offering of LAIs to patients who may benefit from them. For example, general practitioners (who may not be as well versed in new mental health treatments) tend to prescribe FGA-LAIs more frequently than SGALAIs - the opposite of what is observed for psychiatrists [76]. Also, clinicians with more experience treating patients with schizophrenia and general experience with LAIs are more likely to offer and prescribe them [23].

Additionally, mental health clinics that serve the population of patients with schizophrenia are often underfunded, and there are barriers to establishing a proper infrastructure and education for staff, care providers, and patients [77].
The appropriate infrastructure with specialized mental health clinics and support from experienced clinicians can provide the proper resources to prepare and administer injections and implement more developed adherence monitoring techniques (increased consultation frequency/psychosocial interventions) for patients who are skeptical of their need for treatment $[14,23,62]$.

Education and training of clinicians, along with resource assessment, are all critical factors to providing the proper framework for clinicians to increase LAI acceptance in patients. Clinicians need to be trained early on how to properly discuss LAIs with patients to accurately describe the benefits of LAIs and encourage their use when appropriate. A knowledge base around frequently asked questions (e.g., efficacy of LAIs vs. OAs, side effects, control over injections) is critical to successful conversations with patients [78], and an infrastructure of coordinated care can be developed to help many patients better navigate their long-term treatment.

\section{How Should Clinicians Address Patients Who Balk at Recommendations for LAls?}

\subsection{Patient and Caregiver Education}

Another relevant factor influencing a lack of LAI use is patient refusal [23]. Resistance to initiating an LAI after the first episode of schizophrenia can be attributed to a lack of acceptance of the diagnosis or insufficient awareness of the importance of maintenance medication and how strongly the disease will impact daily living if relapses occur more frequently or are allowed to occur at all [12]. While LAIs may no longer be burdened with the historical misperception of being used as a punishment or as a means of control, community treatment orders utilized in some localities may contribute to negative perceptions still held by patients. Patients may also be concerned about the stigma associated with the old paradigm of LAIs being used only in the most chronically and severely ill patients or in "bad" patients who are violent or are not truthful about their level of adherence in addition to the stigma of having to return to mental healthcare facilities to receive injections, rather than simply filling a prescription at a local pharmacy [12]. Combining these reasons with anxiety over medication side effects or needles [12, 18, 23], patients may be apprehensive about using an LAI, requiring a thoughtful approach to presenting LAIs as a therapy option.

A necessary step to improve the perception of LAIs and aid the treatment decision-making process is to provide educational material to patients and caretakers. Providing patients with information about their disease and treatment options can help them become more engaged in the 
conversation about the most appropriate treatment choices [79]. Educational elements should be provided to both the patient and family members to support a shared decisionmaking process among the patient, family members, and healthcare team [62], which in turn can improve patient outcomes [79]. Education can focus on some of the reported benefits of LAIs over OAs, as discussed previously. For patients who resist LAI use from a purely financial co-pay perspective, economic burden and healthcare resource utilization (inpatient/outpatient visits and associated co-pay) can be lower with implementation of LAI use, offsetting any potential higher costs of medication $[60,76,80]$.

Both patients and clinicians are interested in preventing relapse, and educational material can help address patient concerns and facilitate development of a positive clinician-patient relationship. One survey identified that the ability of an LAI to reduce the risk of relapse was significantly associated with patient acceptance of its use [18]. Additional information on the greater efficacy of LAIs over OAs should be made clear in materials provided to patients.

One questionnaire revealed that patients with experience taking LAIs had a very different perception of the injectable formulations than those taking OAs [18]. In this survey, most patients taking OAs believed that LAIs were painful, did not provide better relapse prevention, and had worse side effects than their current OAs [18]. The converse was true for patients taking LAIs, with the majority feeling that side effects were milder and relapse prevention/efficacy was better with LAIs [18]. Furthermore, less than one-third of the LAI-treated patient group in this study felt that the treatment was painful [18]. Patients resistant to LAI use may find it useful to learn about the experiences and opinions of their peers with more familiarity with LAIs when considering their own treatment options. One study reported that the majority (67\%) of those who received LAIs reported feelings of being less anxious or depressed and feeling more energetic [65]. Patients naïve to LAI use may be more receptive to the perspectives of patients with LAI experience than merely reading general information or receiving clinician feedback.

Each patient is unique, and, like treatment [39], educational material should be tailored to an individual's needs for their personal diagnosis and disease state. For example, patients' concerns about LAI use are largely associated with concerns about side effects [23]; therefore, these patients should receive specific information on the occurrence and management of treatment-related adverse events. Even patients who feel a high necessity for treatment can be concerned over the safety of LAI use [23]. Patients also may not be aware that some LAIs provide multiple injection-site options [26], which in turn could increase their comfort level with the process and reduce potential issues from repeated use of one injection area. Additionally, deltoid versus gluteal injections may be better accepted by some patients [8].

\subsection{Caregiver Involvement}

Some patients may be resistant to LAI use regardless of what educational material is provided. Notably, schizophrenia is characterized by broad cognitive impairment-including differences in attention, memory, and executive function $[81,82]$ — which could hinder how well patients understand their condition, its functional impact, and the need for treatment. The degree to which patients believe they are in need of treatment varies, and patients who are unaware of their symptoms tend to have smaller brain size and intracranial volume than their diagnosed peers who are aware of their symptoms [83]. Importantly, insight of patients may not improve over time, with one study reporting that, over the first 24 months of receiving an LAI, there were no significant improvements in illness awareness or attribution of symptoms to schizophrenia as measured on the Birchwood Insight Scale [84].

Patients need to be informed of the details of their condition; however, family members should also be involved whenever possible to potentially facilitate interactions and improve chances of treatment success. Implementing patient-centered care, including involvement of a broader support network, may help empower patients in the treatment process [14]. Many patients with schizophrenia have a reduced understanding and acceptance of their condition, and the role of the family and caregivers, and the potential use of incentives should each be considered when developing a treatment approach. Families are often the first to witness/experience the consequences of a relapse and have a strong investment in relapse prevention.

\subsection{Financial Incentives}

One mechanism to facilitate the appropriate use of LAIs and to reduce personal, interpersonal, illness, and healthcare burden could be to provide a financial incentive to patients for agreeing to use the medication. Evidence to support financial incentives with LAIs has been reported in two clinical trials of patients with schizophrenia $[85,86]$. In the study by Priebe et al. [86], patients with less than $75 \%$ baseline adherence were randomized to receive either $£ 15$ per LAI treatment or LAI treatment without incentive. After 12 months, adherence in the financial incentive group increased to $85 \%$, whereas adherence in the control group was relatively unchanged $(71 \%)$. Notably, adherence improvements were not maintained after the study once incentives were no longer provided [86]. Additional assessments in this study reported not only statistically significant improvements in adherence for the incentive group but also significant 
improvements in quality of life and the patient-clinician relationship [86]. Two reasons for relationship improvement were a higher patient perception of feeling valued and a more nurtured relationship from more frequent appointments [86]. In a study from the Netherlands, patients initiated LAI treatment with or without an associated $€ 30$ per month (if adherent) [85]. At 12 months, the rate of received/ prescribed LAI doses was significantly higher for patients in the incentive group than for those in the control group (94.3 vs. $80.3 \% ; p<0.0001)$. In contrast to the Priebe et al. [86] study, more patients in the LAI group continued to receive their medication throughout the 6-month follow-up period after cessation of the financial incentive compared with the control group [85]. Notably, increased costs for providers or payers may be a concern with the use of incentives. The Priebe et al. [86] incentive study conducted a cost analysis and reported that, although finances for patient care were slightly higher in the intervention group than in the control group, it was largely because of a significantly higher level of community mental health service costs and not because of the financial incentive itself.

Implementation of incentives will likely be region dependent because of restrictions in certain countries/areas. Ethical concerns appear to be most frequently tied to psychiatric paternalism, which includes coercion, loss of patient autonomy, and damage to the therapeutic relationship [87]. Generally, coercion involves forcing someone into a position of no choice (e.g., threats, physical restraint) [88]; therefore, offering an incentive would not fall into this category because they are presented as a preferred option and not as a threat. Comparatively, healthcare incentives exist for other situations, such as quitting smoking and getting more exercise; therefore, inclusion of a financial incentive to receive a necessary or beneficial mental health treatment could be considered comparable. A financial connection already exists between patients and LAIs: insurance coverage, billing procedure, and overall cost are each (at times) considered barriers to LAI use [60]. When approaching patients with the incentive option, healthcare providers should note that many patients likely have other financial concerns in addition to healthcare costs that should also be addressed [23], and the incentive amount should be reasonable so as not to appear as a means of financial aid [89].

\section{Conclusions}

LAIs provide several therapeutic advantages over OAs, and access should be provided to all patients who may benefit from their use. This includes the traditionally considered patient groups and clinical scenarios-such as nonadherence, multiple relapses, self-harm/intent to harm others, substance abuse [60] - but also more proactive and preventive utilization of LAIs in patients with first-episode psychosis and early-phase schizophrenia [21]. Several arguments perpetuating a negative perception of LAIs exist; however, many of these issues are unsupported by current data and can be countered with proper education and training efforts. As shown in Table 2, these perceptions range across the controversy categories described earlier. Treatment of schizophrenia is a long-term commitment, and patients should be provided the best chance of success early on, which includes the medication that will result in the highest adherence, greatest efficacy, and fewest discontinuations because of patient discomfort [90].

One model to increase LAI knowledge and consideration is shown in Fig. 1. First, educating and training treatment providers on the benefits of LAIs, available SGA-LAI options, and how to discuss LAIs with patients are critical steps to increasing access to this effective medication formulation to patients in need of better treatment options and improved outcomes. In the PRELAPSE trial involving patients with first-episode psychosis and early-phase disease, there was a strong acceptance of possible LAI use (86\%), and $91 \%$ of eligible consenting patients went on to receive at least one injection of LAIs after staff received training and education on LAIs in the following areas: rationale for early LAI implementation, shared decision-making strategies, preparation for frequently asked questions about LAIs, and role playing among clinicians to overcome barriers [78].

Once clinicians are properly informed and trained, they should also develop an appropriate system for presenting LAIs as a treatment option to their patients. Patients often feel that clinicians overestimate their own awareness of the patient perspective and would appreciate more interaction and discussion on patient desires and personal preferences [12]. A stepwise shared decision model that involves several strategies of patient interaction can help address these issues and ultimately lead to a greater chance of treatment success $[62,79]$. In such a model, clinicians would work with the patient and any family members/caregivers who will be involved in the treatment process, provide educational information, discuss the patient's diagnosis and potential outcomes if the condition is untreated, develop a system of working together, and establish treatment goals in a manner that is accessible and acceptable to patients [91]. Additionally, an understanding of the patient's feelings and thoughts toward their diagnosis and treatment can be established during these discussions and provide the basis for motivational interviewing and shared decisionmaking steps. The use of decision aids may facilitate this process and increase patient participation in decision making. These may include information on the shared decision-making framework and available treatments as well as questions to help patients identify their concerns and preferences [91]. 

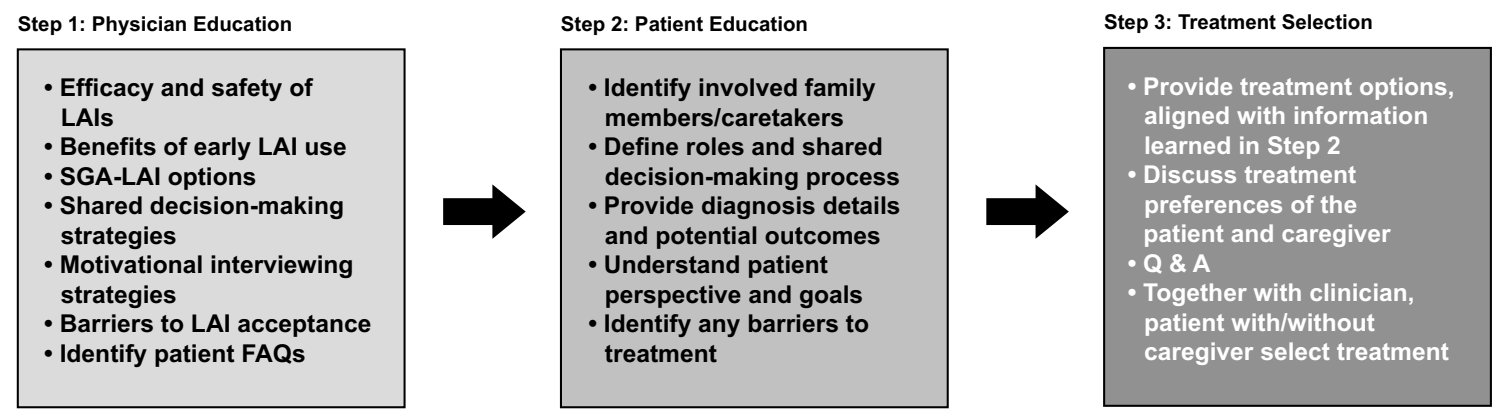

Fig. 1 LAI education and shared decision-making process. FAQs frequently asked questions, LAI long-acting injectable, $S G A$ second-generation antipsychotic, $Q \& A$ question and answer

Once this second step is complete, the clinician can provide treatment options, clearly outlining the pros and cons of various regimens, keeping in mind their ethical obligation to discuss potential treatment options based on clinical evidence rather than unsupported perceptions. Then, these aspects can be aligned with individual patient characteristics, the patient's support network, patient goals and preferences, and any potential barriers that were identified during the second step. Once options are thoroughly discussed and understood, the patient and caregiver can review their preferences, ask questions of the clinician, and make what they feel is the optimal treatment decision.

Improving the informed perception of LAIs and increasing their appropriate consideration begins with proper education and training. Development of a shared decision-making process and a coordinated care infrastructure among the clinicians, nurses, therapists, case managers, education and employment specialists, and pharmacists involved in patient care is a worthwhile investment for the long-term treatment of schizophrenia. A reported fear of clinicians has been the reduction of patient autonomy with use of LAIs. However, with this system, patients are involved in their care and have a greater chance of gaining autonomy over their illness and making impactful steps toward improved outcomes and quality of life.

Acknowledgements Medical writing support for the development of this manuscript, under the direction of the authors, was provided by Kelly M. Fahrbach, PhD, and Jane Kim, PhD, of Ashfield MedComms, an Ashfield Health company, and funded by Teva Pharmaceutical Industries. Editorial support was provided by Jason Tuffree of Ashfield MedComms, an Ashfield Health company, and funded by Teva Pharmaceutical Industries.

\section{Declarations}

Funding Funding for this publication and editorial support was provided by Teva Pharmaceutical Industries, West Chester, PA, USA.

Conflicts of Interest John M. Kane has been a consultant for or received honoraria from Alkermes, Intra-Cellular Therapies, Jans- sen, Johnson and Johnson, Karuna, LB Pharmaceuticals, Lundbeck, Lyndra, Merck, Neurocrine Biosciences, Otsuka, Pierre Fabre, Reviva, Roche, Saladex, Sunovion, Takeda, and Teva Pharmaceutical Industries; has received grant support from Otsuka, Lundbeck, and Janssen; and is a shareholder of LB Pharmaceuticals and Vanguard Research Group. Joseph P. McEvoy has received grant/research support from Alkermes, Auspex Pharmaceuticals (Teva Pharmaceutical Industries), Biogen, Boehringer Ingelheim, Lundbeck, and Takeda and has served on advisory boards for Intra-Cellular Therapies and Sunovion. Christoph U. Correll has been a consultant for or has received honoraria from AbbVie, Acadia Pharmaceuticals, Alkermes, Allergan, Angelini, Axsome Therapeutics, Gedeon Richter, IntraCellular Therapies, Janssen, Johnson \& Johnson, Karuna, LB Pharmaceuticals, Laboratorios Farmacéuticos ROVI, Lundbeck, MedAvante-ProPhase, MedInCell, Medscape, Merck, Mitsubishi Tanabe Pharma, Mylan, Neurocrine, Noven, Otsuka, Pfizer, Recordati, Seqirus, Servier, Sumitomo Dainippon, Sunovion, Supernus Pharmaceuticals, Takeda, Teva Pharmaceutical Industries, and Viatris; has provided expert testimony for Janssen and Otsuka; has served on data safety monitoring boards or advisory boards for Laboratorios Farmacéuticos ROVI, Lundbeck, Supernus, and Teva Pharmaceutical Industries; has received grant support from Janssen and Takeda; has received royalties from UpToDate; serves on the board of directors for the American Society of Clinical Psychopharmacology; and is a shareholder of LB Pharmaceuticals. Pierre-Michel Llorca has been a consultant for or has received honoraria from AbbVie, Allergan, Eisai, Gedeon Richter, Janssen, Lundbeck, Otsuka, Sanofi, and Teva Pharmaceutical Industries; has received travel support from Eisai, Lundbeck, and Janssen; has served on data safety monitoring boards or advisory boards for AbbVie, Allergan, Eisai, Janssen, Lundbeck, Otsuka, Sanofi, and Teva Pharmaceutical Industries; and has received grant support from and provided expert testimony for Janssen.

Availability of data and material Not applicable.

Code availability Not applicable

Ethics approval Not applicable

Consent Not applicable

Author contributions All authors contributed equally to the conception, literature review, drafting, and review processes related to this publication. All authors approved the final version of the manuscript for submission and agree to be accountable for the information presented in this publication. 
Open Access This article is licensed under a Creative Commons Attribution-NonCommercial 4.0 International License, which permits any non-commercial use, sharing, adaptation, distribution and reproduction in any medium or format, as long as you give appropriate credit to the original author(s) and the source, provide a link to the Creative Commons licence, and indicate if changes were made. The images or other third party material in this article are included in the article's Creative Commons licence, unless indicated otherwise in a credit line to the material. If material is not included in the article's Creative Commons licence and your intended use is not permitted by statutory regulation or exceeds the permitted use, you will need to obtain permission directly from the copyright holder. To view a copy of this licence, visit http://creativecommons.org/licenses/by-nc/4.0/.

\section{References}

1. GBD 2017 Disease and Injury Incidence and Prevalence Collaborators. Global, regional, and national incidence, prevalence, and years lived with disability for 354 diseases and injuries for 195 countries and territories, 1990-2017: a systematic analysis for the Global Burden of Disease Study 2017. Lancet. 2018;392(10159):1789-858. https://doi.org/10.1016/S01406736(18)32279-7.

2. McGrath J, Saha S, Chant D, Welham J. Schizophrenia: a concise overview of incidence, prevalence, and mortality. Epidemiol Rev. 2008;30:67-76. https://doi.org/10.1093/epirev/mxn001.

3. Girardi P, Del Casale A, Rapinesi C, Kotzalidis GD, Splendori $\mathrm{F}$, Verzura C, et al. Predictive factors of overall functioning improvement in patients with chronic schizophrenia and schizoaffective disorder treated with paliperidone palmitate and aripiprazole monohydrate [published correction appears in Hum Psychopharmacol. 2018;33(4):e2666]. Hum Psychopharmacol. 2018;33(3):e2658. https://doi.org/10.1002/hup.2658.

4. Higashi K, Medic G, Littlewood KJ, Diez T, Granstrom O, De Hert M. Medication adherence in schizophrenia: factors influencing adherence and consequences of nonadherence, a systematic literature review. Ther Adv Psychopharmacol. 2013;3(4):200-18. https://doi.org/10.1177/2045125312474019.

5. MacEwan JP, Forma FM, Shafrin J, Hatch A, Lakdawalla DN, Lindenmayer JP. Patterns of adherence to oral atypical antipsychotics among patients diagnosed with schizophrenia. J Manag Care Spec Pharm. 2016;22(11):1349-61. https://doi.org/10. 18553/jmcp.2016.22.11.1349.

6. Penttilä M, Jääskeläinen E, Hirvonen N, Isohanni M, Miettunen J. Duration of untreated psychosis as predictor of long-term outcome in schizophrenia: systematic review and meta-analysis. $\mathrm{Br}$ J Psychiatry. 2014;205(2):88-94. https://doi.org/10.1192/bjp.bp. 113.127753.

7. Howes OD, Whitehurst T, Shatalina E, Townsend L, Onwordi EC, Mak TLA, et al. The clinical significance of duration of untreated psychosis: an umbrella review and random-effects meta-analysis. World Psychiatry. 2021;20(1):75-95. https://doi.org/10.1002/wps. 20822.

8. Geerts P, Martinez G, Schreiner A. Attitudes towards the administration of long-acting antipsychotics: a survey of physicians and nurses. BMC Psychiatry. 2013;13:58. https://doi.org/10.1186/ 1471-244X-13-58.

9. Kane JM, Kishimoto T, Correll CU. Non-adherence to medication in patients with psychotic disorders: epidemiology, contributing factors and management strategies. World Psychiatry. 2013;12(3):216-26. https://doi.org/10.1002/wps.20060.

10. Brissos S, Veguilla MR, Taylor D, Balanzá-Martinez V. The role of long-acting injectable antipsychotics in schizophrenia: a critical appraisal. Ther Adv Psychopharmacol. 2014;4(5):198219. https://doi.org/10.1177/2045125314540297.

11. Carbon M, Correll CU. Clinical predictors of therapeutic response to antipsychotics in schizophrenia. Dialogues Clin Neurosci. 2014;16(4):505-24. https://doi.org/10.31887/DCNS. 2014.16.4/mcarbon.

12. Pietrini F, Albert U, Ballerini A, Calo P, Maina G, Pinna F, et al. The modern perspective for long-acting injectables antipsychotics in the patient-centered care of schizophrenia. Neuropsychiatr Dis Treat. 2019;15:1045-60. https://doi.org/10.2147/NDT. S199048.

13. Samalin L, de Chazeron I, Blanc O, Brunel L, Fond G, Llorca PM. Attitudes toward antipsychotic medications as a useful feature in exploring medication non-adherence in schizophrenia. Schizophr Res. 2016;178(1-3):1-5. https://doi.org/10.1016/j.schres.2016.09. 015 .

14. Correll CU, Citrome L, Haddad PM, Lauriello J, Olfson M, Calloway SM, et al. The use of long-acting injectable antipsychotics in schizophrenia: evaluating the evidence. J Clin Psychiatry. 2016;77(suppl 3):1-24. https://doi.org/10.4088/JCP.15032su1.

15. Correll CU, Kim E, Sliwa JK, Hamm W, Gopal S, Mathews $\mathrm{M}$, et al. Pharmacokinetic characteristics of long-acting injectable antipsychotics for schizophrenia: an overview. CNS Drugs. 2021;35(1):39-59. https://doi.org/10.1007/s40263-020-00779-5.

16. Taylor DM, Velaga S, Werneke U. Reducing the stigma of long acting injectable antipsychotics - current concepts and future developments published correction appears in Nord J Psychiatry. 2021;1]. Nord J Psychiatry. 2018;72(sup1):S36-9. https://doi.org/ $10.1080 / 08039488.2018 .1525638$.

17. De Alarcon R, Carney MW. Severe depressive mood changes following slow-release intramuscular fluphenazine injection. Br Med J. 1969;3(5670):564-7. https://doi.org/10.1136/bmj.3.5670.564.

18. Sugawara N, Kudo S, Ishioka M, Sato Y, Kubo K, Yasui-Furukori N. Attitudes toward long-acting injectable antipsychotics among patients with schizophrenia in Japan. Neuropsychiatr Dis Treat. 2019;15:205-11. https://doi.org/10.2147/NDT.S188337.

19. Correll CU, Litman RE, Filts Y, Llaudó J, Naber D, Torres F, et al. Efficacy and safety of once-monthly Risperidone ISM(®) in schizophrenic patients with an acute exacerbation. NPJ Schizophr. 2020;6(1):37. https://doi.org/10.1038/s41537-020-00127-y.

20. Solmi M, Murru A, Pacchiarotti I, Undurraga J, Veronese N, Fornaro M, et al. Safety, tolerability, and risks associated with firstand second-generation antipsychotics: a state-of-the-art clinical review. Ther Clin Risk Manag. 2017;13:757-77. https://doi.org/ 10.2147/TCRM.S117321.

21. Kane JM, Schooler NR, Marcy P, Correll CU, Achtyes ED, Gibbons RD, et al. Effect of long-acting injectable antipsychotics vs usual care on time to first hospitalization in early-phase schizophrenia: a randomized clinical trial [published correction appears in JAMA Psychiatry. 2020;77(12):1310]. JAMA Psychiat. 2020;77(12):1217-24. https://doi.org/10.1001/jamapsychiatry. 2020.2076.

22. Subotnik KL, Casaus LR, Ventura J, Luo JS, Hellemann GS, Gretchen-Doorly D, et al. Long-acting injectable risperidone for relapse prevention and control of breakthrough symptoms after a recent first episode of Schizophrenia. A randomized clinical trial. JAMA Psychiat. 2015;72(8):822-9. https://doi.org/10.1001/jamap sychiatry.2015.0270.

23. Samalin L, Garnier M, Auclair C, Llorca PM. Clinical decisionmaking in the treatment of schizophrenia: focus on long-acting injectable antipsychotics. Int J Mol Sci. 2016;17(11):1935. https:// doi.org/10.3390/ijms17111935.

24. 2019-2020 florida best practice psychotherapeutic medication guidelines for adults: University of South Florida, Florida Medicaid Drug Therapy Management Program sponsored by the Florida Agency for Health Care Administration; 2020. https://floridabhc 
enter.cbcs.usf.edu/wp-content/uploads/2021/04/2019-Psychother apeutic-Medication-Guidelines-for-Adults-with-References_0604-20.pdf. Accessed 21 July 21.

25. National Council for Behavioral Health. Guide to long-acting medications for providers and organizations. 2019. https://www. thenationalcouncil.org/wp-content/uploads/2020/05/051220_ NCBH_GuidetoLAMs_Live.pdf. Accessed 10 June 21.

26. Keepers GA, Fochtmann LJ, Anzia JM, Benjamin S, Lyness JM, Mojtabai R, et al. The American Psychiatric Association Practice Guideline for the treatment of patients with schizophrenia. Am J Psychiatry. 2020;177(9):868-72. https://doi.org/10.1176/appi.ajp. 2020.177901.

27. Llorca PM, Abbar M, Courtet P, Guillaume S, Lancrenon S, Samalin L. Guidelines for the use and management of long-acting injectable antipsychotics in serious mental illness. BMC Psychiatry. 2013;13:340. https://doi.org/10.1186/1471-244X-13-340.

28. American Psychiatric Association. The American Psychiatric Association Practice Guideline for the treatment of patients with schizophrenia. 3rd ed; 2021. https://doi.org/10.1176/appi.books. 9780890424841

29. Lacro JP, Dunn LB, Dolder CR, Leckband SG, Jeste DV. Prevalence of and risk factors for medication nonadherence in patients with schizophrenia: a comprehensive review of recent literature. J Clin Psychiatry. 2002;63(10):892-909. https://doi.org/10.4088/ jcp.v63n1007.

30. Stephenson JJ, Tunceli O, Gu T, Eisenberg D, Panish J, Crivera C, et al. Adherence to oral second-generation antipsychotic medications in patients with schizophrenia and bipolar disorder: physicians' perceptions of adherence vs. pharmacy claims. Int J Clin Pract. 2012;66(6):565-73. https://doi.org/10.1111/j.1742-1241. 2012.02918.x.

31. Tiihonen J, Haukka J, Taylor M, Haddad PM, Patel MX, Korhonen P. A nationwide cohort study of oral and depot antipsychotics after first hospitalization for schizophrenia [published correction appears in Am J Psychiatry. 2012;169(2):223]. Am J Psychiatry. 2011;168(6):603-9. https://doi.org/10.1176/appi.ajp.2011.10081 224.

32. Greene M, Yan T, Chang E, Hartry A, Touya M, Broder MS. Medication adherence and discontinuation of long-acting injectable versus oral antipsychotics in patients with schizophrenia or bipolar disorder. J Med Econ. 2018;21(2):127-34. https://doi.org/ 10.1080/13696998.2017.1379412.

33. Laing E, Taylor D. Relapse and frequency of injection of monthly paliperidone palmitate-A retrospective case-control study. Eur Psychiatry. 2021;64(1): e11. https://doi.org/10.1192/j.eurpsy. 2021.4.

34. Pappa S, Mason K. Partial compliance with long-acting paliperidone palmitate and impact on hospitalization: a 6-year mirror-image study. Ther Adv Psychopharmacol. 2020;10:2045125320924789. https://doi.org/10.1177/2045125320 924789.

35. Olfson M, Marcus SC, Ascher-Svanum H. Treatment of schizophrenia with long-acting fluphenazine, haloperidol, or risperidone. Schizophr Bull. 2007;33(6):1379-87. https://doi.org/10. 1093/schbul/sbm033.

36. Weiden PJ, Kim E, Bermak J, Turkoz I, Gopal S, Berwaerts J. Does half-life matter after antipsychotic discontinuation? A relapse comparison in schizophrenia with 3 different formulations of paliperidone. J Clin Psychiatry. 2017;78(7):e813-20. https:// doi.org/10.4088/JCP.16m11308.

37. Kishimoto T, Hagi K, Kurokawa S, Kane JM, Correll CU. Longacting injectable versus oral antipsychotics for the maintenance treatment of schizophrenia: a systematic review and comparative meta-analysis of randomised, cohort, and pre-post studies. Lancet Psychiatry. 2021;8(5):387-404. https://doi.org/10.1016/ S2215-0366(21)00039-0.
38. Bossie CA, Alphs LD, Correll CU. Long-acting injectable versus daily oral antipsychotic treatment trials in schizophrenia: pragmatic versus explanatory study designs. Int Clin Psychopharmacol. 2015;30(5):272. https://doi.org/10.1097/YIC.00000 00000000082.

39. Novick D, Haro JM, Bertsch J, Haddad PM. Incidence of extrapyramidal symptoms and tardive dyskinesia in schizophrenia: thirty-six-month results from the European schizophrenia outpatient health outcomes study. J Clin Psychopharmacol. 2010;30(5):531-40. https://doi.org/10.1097/JCP.0b013e3181 f14098.

40. Kane JM, Garcia-Ribera C. Clinical guideline recommendations for antipsychotic long-acting injections. Br J Psychiatry Suppl. 2009;52:S63. https://doi.org/10.1192/bjp.195.52.s63.

41. Caroff SN, Ungvari GS, Cunningham Owens DG. Historical perspectives on tardive dyskinesia. J Neurol Sci. 2018;389:4-9. https://doi.org/10.1016/j.jns.2018.02.015.

42. Misawa F, Kishimoto T, Hagi K, Kane JM, Correll CU. Safety and tolerability of long-acting injectable versus oral antipsychotics: A meta-analysis of randomized controlled studies comparing the same antipsychotics. Schizophr Res. 2016;176(2-3):220. https:// doi.org/10.1016/j.schres.2016.07.018.

43. Noel JM, Jackson CW. ASHP therapeutic position statement on the use of antipsychotic medications in the treatment of adults with schizophrenia and schizoaffective disorder. Am J Health Syst Pharm. 2020;77(24):2114-32. https://doi.org/10.1093/ajhp/zxaa3 03.

44. Guinart D, Misawa F, Rubio JM, Pereira J, Sharma H, Schoretsanitis G, et al. Outcomes of neuroleptic malignant syndrome with depot versus oral antipsychotics: a systematic review and pooled, patient-level analysis of 662 case reports. J Clin Psychiatry. 2020;82(1):20r13272. https://doi.org/10.4088/JCP.20r13272.

45. Emsley R, Chiliza B, Asmal L, Harvey BH. The nature of relapse in schizophrenia. BMC Psychiatry. 2013;13:50. https://doi.org/10. 1186/1471-244X-13-50.

46. Takeuchi H, Siu C, Remington G, Fervaha G, Zipursky RB, Foussias $\mathrm{G}$, et al. Does relapse contribute to treatment resistance? Antipsychotic response in first- vs. second-episode schizophrenia. Neuropsychopharmacology. 2019;44(6):1036-42. https://doi.org/ 10.1038/s41386-018-0278-3.

47. Correll CU, Sliwa JK, Najarian DM, Saklad SR. Practical considerations for managing breakthrough psychosis and symptomatic worsening in patients with schizophrenia on long-acting injectable antipsychotics. CNS Spectr. 2018. https://doi.org/10.1017/S1092 852918001098.

48. Emsley R, Asmal L, Rubio JM, Correll CU, Kane JM. Predictors of psychosis breakthrough during 24 months of long-acting antipsychotic maintenance treatment in first episode schizophrenia. Schizophr Res. 2020;225:55-62. https://doi.org/10.1016/j. schres.2019.11.025.

49. Rubio JM, Taipale H, Correll CU, Tanskanen A, Kane JM, Tiihonen J. Psychosis breakthrough on antipsychotic maintenance: results from a nationwide study. Psychol Med. 2020;50(8):135667. https://doi.org/10.1017/S0033291719001296.

50. Rubio JM, Schoretsanitis G, John M, Tiihonen J, Taipale H, Guinart D, et al. Psychosis relapse during treatment with longacting injectable antipsychotics in individuals with schizophreniaspectrum disorders: an individual participant data meta-analysis. Lancet Psychiatry. 2020;7(9):749-749. https://doi.org/10.1016/ S2215-0366(20)30264-9.

51. Taipale H, Mittendorfer-Rutz E, Alexanderson K, Majak M, Mehtala J, Hoti F, et al. Antipsychotics and mortality in a nationwide cohort of 29,823 patients with schizophrenia. Schizophr Res. 2018;197:274-80. https://doi.org/10.1016/j.schres.2017.12.010. 
52. Taipale H, Tanskanen A, Mehtala J, Vattulainen P, Correll CU, Tiihonen J. 20-year follow-up study of physical morbidity and mortality in relationship to antipsychotic treatment in a nationwide cohort of 62,250 patients with schizophrenia (FIN20). World Psychiatry. 2020;19(1):61-8. https://doi.org/10.1002/wps.20699.

53. Tiihonen J, Tanskanen A, Taipale H. 20-year nationwide followup study on discontinuation of antipsychotic treatment in firstepisode schizophrenia. Am J Psychiatry. 2018;175(8):765-73. https://doi.org/10.1176/appi.ajp.2018.17091001.

54. Seeman MV. Drawbacks of long-acting intramuscular antipsychotic injections. J Clin Pract Nurs. 2017;1(1):12-22.

55. Velligan DI, Sajatovic M, Hatch A, Kramata P, Docherty JP. Why do psychiatric patients stop antipsychotic medication? A systematic review of reasons for nonadherence to medication in patients with serious mental illness. Patient Prefer Adherence. 2017;11:449-68. https://doi.org/10.2147/PPA.S124658.

56. Samalin L, Charpeaud T, Blanc O, Heres S, Llorca PM. Clinicians' attitudes toward the use of long-acting injectable antipsychotics. J Nerv Ment Dis. 2013;201(7):553-9. https://doi.org/10. 1097/NMD.0b013e31829829c4.

57. Sajatovic M, Ross R, Legacy SN, Correll CU, Kane JM, DiBiasi $\mathrm{F}$, et al. Identifying patients and clinical scenarios for use of longacting injectable antipsychotics - expert consensus survey part 1 . Neuropsychiatr Dis Treat. 2018;14:1463. https://doi.org/10.2147/ NDT.S167394.

58. Horvitz-Lennon M, Predmore Z, Orr P, Hanson M, Hillestad R, Durkin M, et al. Simulated long-term outcomes of early use of long-acting injectable antipsychotics in early schizophrenia. Early Interv Psychiatry. 2019;13(6):1357-65. https://doi.org/10.1111/ eip. 12770

59. Guzman F. Long-acting injectable antipsychotics: a practical guide for prescribers. 27 June 2019 [cited 16 June 2020]. https:// psychopharmacologyinstitute.com/publication/long-acting-injec table-antipsychotics-a-practical-guide-for-prescribers-2201.

60. Sajatovic M, Ross R, Legacy SN, Byerly M, Kane JM, DiBiasi F, et al. Initiating/maintaining long-acting injectable antipsychotics in schizophrenia/schizoaffective or bipolar disorder-expert consensus survey part 2. Neuropsychiatr Dis Treat. 2018;14:1475-92. https://doi.org/10.2147/NDT.S167485.

61. Howes OD, McCutcheon R, Agid O, de Bartolomeis A, van Beveren NJ, Birnbaum ML, et al. Treatment-resistant schizophrenia: treatment response and resistance in psychosis (TRRIP) working group consensus guidelines on diagnosis and terminology. Am J Psychiatry. 2017;174(3):216-29. https://doi.org/10.1176/appi.ajp. 2016.16050503.

62. Lauriello J. Patient-centered psychopharmacology and psychosocial interventions: treatment selection and shared decisionmaking to enhance chances for recovery. J Clin Psychiatry. 2020;81(3):MS19053BR4C. https://doi.org/10.4088/JCP.MS190 53BR4C.

63. Correll CU, Lauriello J. Using long-acting injectable antipsychotics to enhance the potential for recovery in schizophrenia. J Clin Psychiatry. 2020;81(4):MS19053AH5C. https://doi.org/10.4088/ JCP.MS19053AH5C.

64. Farooq S, Nazar Z, Irfan M, Akhter J, Gul E, Irfan U, et al. Schizophrenia medication adherence in a resource-poor setting: randomised controlled trial of supervised treatment in out-patients for schizophrenia (STOPS). Br J Psychiatry. 2011;199(6):467-72. https://doi.org/10.1192/bjp.bp.110.085340.

65. Caroli F, Raymondet P, Izard I, Plas J, Gall B, Delgado A. Opinions of French patients with schizophrenia regarding injectable medication. Patient Prefer Adherence. 2011;5:165-71. https://doi. org/10.2147/PPA.S15337.

66. Hargarter L, Bergmans P, Cherubin P, Keim S, Conca A, SerranoBlanco A, et al. Once-monthly paliperidone palmitate in recently diagnosed and chronic non-acute patients with schizophrenia. Expert Opin Pharmacother. 2016;17(8):1043-53. https://doi.org/ 10.1080/14656566.2016.1174692.

67. Brown B, Turkoz I, Mancevski B, Mathews M. Evaluation of paliperidone palmitate long-acting injectable antipsychotic therapy as an early treatment option in patients with schizophrenia. Early Interv Psychiatry. 2020;14(4):428-38. https://doi.org/10.1111/eip. 12868.

68. Kim S, Kim S, Koh M, Choi G, Kim JJ, Paik IH, et al. Effects of long-acting injectable paliperidone palmitate on clinical and functional outcomes in patients with schizophrenia based on illness duration. J Clin Psychiatry. 2021. https://doi.org/10.4088/ JCP. $20 \mathrm{~m} 13446$.

69. Kirschner M, Theodoridou A, Fusar-Poli P, Kaiser S, Jäger M. Patients' and clinicians' attitude towards long-acting depot antipsychotics in subjects with a first episode of psychosis. Ther Adv Psychopharmacol. 2013;3(2):89-99. https://doi.org/10.1177/ 2045125312464106.

70. Correll CU. Recognition of patients who would benefit from LAI antipsychotic treatment: how to assess adherence. J Clin Psychiatry. 2014;75(11): e29. https://doi.org/10.4088/JCP.13024tx3c.

71. Weiden PJ, Roma RS, Velligan DI, Alphs L, DiChiara M, Davidson $\mathrm{B}$. The challenge of offering long-acting antipsychotic therapies: a preliminary discourse analysis of psychiatrist recommendations for injectable therapy to patients with schizophrenia. J Clin Psychiatry. 2015;76(6):684-90. https://doi.org/10.4088/JCP. $13 \mathrm{~m} 08946$.

72. Working Group of the Clinical Practice Guideline for Schizophrenia and Incipient Psychotic Disorder, Mental Health Forum, coordination. Clinical Practice Guideline for Schizophrenia and Incipient Psychotic Disorder. Clinical Practice Guideline: CAHTA. Number 2006/05-2. Madrid: Quality Plan for the National Health System of the Ministry of Health and Consumer Affairs. Agency for Health Technology Assessment and Research; 2009. https:// portal.guiasalud.es/wp-content/uploads/2019/01/GPC_495_Schiz ophrenia_compl_en.pdf. Accessed 26 July 2021.

73. Galletly C, Castle D, Dark F, Humberstone V, Jablensky A, Killackey E, et al. Royal Australian and New Zealand College of Psychiatrists clinical practice guidelines for the management of schizophrenia and related disorders. Aust N Z J Psychiatry. 2016;50(5):410-72. https://doi.org/10.1177/0004867416641195.

74. Lo TL, Warden M, He Y, Si T, Kalyanasundaram S, Thirunavukarasu M, et al. Recommendations for the optimal care of patients with recent-onset psychosis in the Asia-Pacific region. Asia Pac Psychiatry. 2016;8(2):154-71. https://doi.org/10.1111/appy. 12234.

75. Robinson DG, Subramaniam A, Fearis PJ, Shi R, Walsh M, Hanna LA, et al. Focused ethnographic examination of barriers to use of long-acting injectable antipsychotics. Psychiatr Serv. 2020;71(4):337-42. https://doi.org/10.1176/appi.ps.201900236.

76. Stip E, Lachaine J. Real-world effectiveness of long-acting antipsychotic treatments in a nationwide cohort of 3957 patients with schizophrenia, schizoaffective disorder and other diagnoses in Quebec [published correction appears in Ther Adv Psychopharmacol. 2018;8(11):327]. Ther Adv Psychopharmacol. 2018;8(11):287-301. https://doi.org/10.1177/2045125318782694.

77. Velligan DI, Medellin E, Draper M, Maples N, Dassori A, Moore TA, et al. Barriers to, and strategies for, starting a long acting injection clinic in a community mental health center. Community Ment Health J. 2011;47(6):654-9. https://doi.org/10.1007/ s10597-011-9389-6.

78. Kane JM, Schooler NR, Marcy P, Achtyes ED, Correll CU, Robinson DG. Patients with early-phase schizophrenia will accept treatment with sustained-release medication (long-acting injectable antipsychotics): results from the recruitment phase of the 
PRELAPSE trial. J Clin Psychiatry. 2019;80(3):18312546. https:// doi.org/10.4088/JCP.18m12546.

79. Hamann J, Heres S. Why and how family caregivers should participate in shared decision making in mental health. Psychiatr Serv. 2019;70(5):418-21. https://doi.org/10.1176/appi.ps.20180 0362.

80. Latorre V, Papazacharias A, Lorusso M, Nappi G, Clemente P, Spinelli A, et al. Improving the "real life" management of schizophrenia spectrum disorders by LAI antipsychotics: a one-year mirror-image retrospective study in community mental health services. PLoS ONE. 2020;15(3): e0230051. https://doi.org/10. 1371/journal.pone.0230051.

81. Heinrichs RW, Zakzanis KK. Neurocognitive deficit in schizophrenia: a quantitative review of the evidence. Neuropsychology. 1998;12(3):426-45. https://doi.org/10.1037//0894-4105.12.3.426.

82. Millan MJ, Agid Y, Brune M, Bullmore ET, Carter CS, Clayton NS, et al. Cognitive dysfunction in psychiatric disorders: characteristics, causes and the quest for improved therapy. Nat Rev Drug Discov. 2012;11(2):141-68. https://doi.org/10.1038/nrd3628.

83. Flashman LA, McAllister TW, Andreasen NC, Saykin AJ. Smaller brain size associated with unawareness of illness in patients with schizophrenia. Am J Psychiatry. 2000;157(7):1167-9. https://doi. org/10.1176/appi.ajp.157.7.1167.

84. Phahladira L, Asmal L, Kilian S, Chiliza B, Scheffler F, Luckhoff HK, et al. Changes in insight over the first 24 months of treatment in schizophrenia spectrum disorders. Schizophr Res. 2019;206:394-9. https://doi.org/10.1016/j.schres.2018.10.013.

85. Noordraven EL, Wierdsma AI, Blanken P, Bloemendaal AF, Staring $\mathrm{AB}$, Mulder CL. Financial incentives for improving adherence to maintenance treatment in patients with psychotic disorders (Money for Medication): a multicentre, open-label, randomised controlled trial. Lancet Psychiatry. 2017;4(3):199-207. https:// doi.org/10.1016/S2215-0366(17)30045-7.

86. Priebe S, Bremner SA, Lauber C, Henderson C, Burns T. Financial incentives to improve adherence to antipsychotic maintenance medication in non-adherent patients: a cluster randomised controlled trial. Health Technol Assess. 2016;20(70):1-122. https:// doi.org/10.3310/hta20700.

87. Claassen D. Financial incentives for antipsychotic depot medication: ethical issues. J Med Ethics. 2007;33(4):189-93. https://doi. org/10.1136/jme.2006.016188.

88. Wertheimer A. A philosophical examination of coercion for mental health issues. Behav Sci Law. 1993;11:239-58.

89. Guinart D, Kane JM. Use of behavioral economics to improve medication adherence in severe mental illness. Psychiatr Serv. 2019;70(10):955-7. https://doi.org/10.1176/appi.ps.201900116.

90. Correll CU, Rubio JM, Kane JM. What is the risk-benefit ratio of long-term antipsychotic treatment in people with schizophrenia? World Psychiatry. 2018;17(2):149-60. https://doi.org/10.1002/ wps.20516.

91. Alguera-Lara V, Dowsey MM, Ride J, Kinder S, Castle D. Shared decision making in mental health: the importance for current clinical practice. Australas Psychiatry. 2017;25(6):578-82. https://doi. org/10.1177/1039856217734711.

92. Foster A, Buckley P, Lauriello J, Looney S, Schooler N. Combination antipsychotic therapies: an analysis from a longitudinal pragmatic trial. J Clin Psychopharmacol. 2017;37(5):595-9. https:// doi.org/10.1097/JCP.0000000000000766.

93. Taipale H, Mehtala J, Tanskanen A, Tiihonen J. Comparative effectiveness of antipsychotic drugs for rehospitalization in schizophrenia-a nationwide study with 20-year follow-up [published correction appears in Schizophr Bull. 2019;45(6):1381]. Schizophr Bull. 2018;44(6):1381-7. https://doi.org/10.1093/schbul/sbx176.

94. Carbon M, Kane JM, Leucht S, Correll CU. Tardive dyskinesia risk with first- and second-generation antipsychotics in comparative randomized controlled trials: a meta-analysis. World Psychiatry. 2018;17(3):330-40. https://doi.org/10.1002/wps.20579. 